\title{
Numerical study of a fully confined supersonic slot impinging jet from bleed system
}

\author{
Tinglong Huang ${ }^{\mathrm{a}, \mathrm{b}}$, Lianjie Yue ${ }^{\mathrm{a}, \mathrm{b}, *}$, Xinyu Chang ${ }^{\mathrm{a}, \mathrm{b}}$ \\ a State Key Laboratory of High Temperature Gas Dynamics, Institute of Mechanics, Chinese Academy of Sciences, No. 15 Beisihuanxi Road, Beijing, 100190 , China \\ b School of Engineering Science, University of Chinese Academy of Sciences, Beijing 100049, China
}

\section{A R T I C L E I N F O}

\section{Article history:}

Received 2 January 2019

Received in revised form 6 April 2019

Accepted 12 April 2019

Available online 16 April 2019

\section{Keywords:}

Fully confined supersonic jet

Inclined impingement

Heat transfer

Boundary layer bleed

Numerical simulation

\begin{abstract}
A B S T R A C T
A supersonic slot jet issuing from a bleed system and impinging into a plenum is numerically investigated to deepen our understanding of the flow field and heat transfer of a fully confined impinging jet. The air of the slot jet is forced to exhaust from a plenum in unidirection, resulting in a fully confined configuration. It is of significant practical interest because of its presence in the bleed systems of a scramjet or other related applications. Three primary factors are surveyed, i.e., impingement angle, impingement distance, and back pressure at the plenum exit. The results show that the supersonic slot jet spontaneously generates a plate shock standing on the impingement wall and a strong jet shock on the right side of the jet core. On the left side, the jet shear layer can directly impinge the wall because of the pressure self-adaption effect of a recirculation region. The jet shock and jet shear layer result in two peaks of Stanton number. As the impingement angle increases, the jet shock weakens gradually and moves toward the impingement region of the shear layer until the shock disappears. And thus a single heat peak occurs in place of the previous two peaks. When the downstream flow of the plenum is choked, a wall jet pattern is exhibited because of the formation of a large scale recirculation region. The walls suffer severe aerodynamic heating as the plenum back pressure increases. In particular, the impingement wall endures the maximum thermal load at a certain back pressure at which the jet reduces to the sound speed. The plenum should be controlled to keep the back pressure below this threshold so that the slot walls Stanton number won't increase further. And the plenum should be designed as high as possible to relieve its thermal load.
\end{abstract}

(c) 2019 Elsevier Masson SAS. All rights reserved.

\section{Introduction}

Scramjet engines are expected to become a promising candidate of the propulsion unit for future space transportation systems. The internal flow path features some complex flow phenomena. Different types of irreversible processes are involved, such as shocks and shock-induced boundary layer separations [1]. Boundary layer separations are always associated with drag increase and pressure recovery losses, and the separations near the inlet throat can possibly trigger inlet unstart and promote engine stall. As one of the most powerful methods to suppress boundary layer separations, bleed systems have been introduced into scramjet design. Schulte et al. [2,3] examined the influence of bleed configuration parameters, such as bleed slot width, slot angle and slot position, on the bleed efficiency in hypersonic inlets. A position of bleed slot di-

\footnotetext{
* Corresponding author at: Institute of Mechanics, Chinese Academy of Sciences, No. 15 Beisihuanxi Road, Beijing, 100190, China.

E-mail address: yuelj@imech.ac.cn (LJ. Yue).
}

rectly upstream of the shock impingement location was found the most favorable. The implementation of a bleed system can lead to a significant increase in the attainable total pressure recovery of hypersonic inlets, as well as a reduction in the separation bubble size. Häberle and Gülhan [4,5] employed a passive bleed slot at the throat of a fixed geometry hypersonic inlet to greatly diminish the lip shock-induced separation bubble on the ramp and reduce the risk of inlet unstart. Mitani et al. [6,7] also found that the bleeding of $0.65 \%$ in captured airflow suppressed effectively the boundary layer separation, improved the unstart characteristics in engines and doubled the engine operating range. Weiss and Oliver [8] and Donbar et al. [9] further showed that the back pressure of the shock train in a scramjet isolator could be increased until the shock train gradually changed into a single normal shock because the slot suction would stabilize the primary shock foot. Xing et al. [10] investigated the scramjet engine and used the bleed slot to prevent the shock train from moving upstream. He et al. [11] employed a bleed slot to control the separation of corner flow in the isolator and found that a spanwise bleed slot on the side wall can shorten effectively the length of shock train. Additionally, Falempin 


\section{Nomenclature}

$C_{p} \quad$ specific heat at constant pressure ........... J/kg K

$d \quad$ bleed slot opening width.................. mm

D nozzle diameter

$h \quad$ plenum height $\ldots \ldots \ldots \ldots \ldots \ldots \ldots \ldots \ldots \ldots \ldots, \mathrm{mm}$

$k \quad$ turbulence kinetic energy

M Mach number

$p \quad$ pressure $\ldots \ldots \ldots \ldots \ldots \ldots \ldots \ldots \ldots \ldots \ldots \ldots \ldots \ldots \ldots \ldots$

$P \quad$ total pressure $\ldots \ldots \ldots \ldots \ldots \ldots \ldots \ldots \ldots \ldots \ldots \ldots$

pr pressure ratio

$q \quad$ heat flux ................................

$R \quad$ radial coordinate

Re Reynold number

St Stanton number

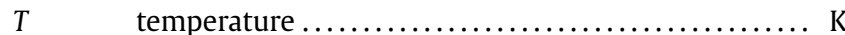

U velocity $\ldots \ldots \ldots \ldots \ldots \ldots \ldots \ldots \ldots \ldots \ldots \ldots \ldots \ldots, \mathrm{m} / \mathrm{s}$

$x, y \quad$ coordinate system $\ldots \ldots \ldots \ldots \ldots \ldots \ldots \ldots \ldots, \mathrm{mm}$

$y^{+} \quad$ the height of the first mesh cell off the wall in wall coordinate

\section{Greek letters}

$\delta$ $\eta$

$\theta$

$\rho$

$\omega$

boundary layer thickness ................... mm normalized Stanton number

impingement angle

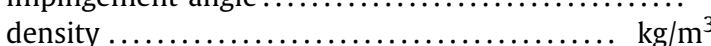

\section{Sub/superscript}

0 total or stagnation state

1 free stream conditions

a ambient state

$b \quad$ location at the plenum exit

max maximum value

$u \quad$ upstream slot wall

$w \quad$ wall surface et al. [12], Chang et al. [13] and Pandian et al. [14] adopted the bleed as an efficient method to facilitate inlet starting and improve their overall characteristics. The aforementioned studies argue that the boundary layer bleed can provide huge potential benefits for hypersonic inlets.

Although the bleed can reduce vortex-induced highly localized thermal loads by eliminating the boundary layer separation [2,3], the bleed slots themselves would suffer from aerothermal loads at hypersonic conditions. The high temperature flow passing into the bleed slot or holes makes hostile environment for the bleed system. Besides the maximum thermal load at the stagnation point of the bleed corner, Yue et al. [15] found a localized high heat flux within the slot passage. This peak flux arises from the boundary layer separation triggered by the bleed barrier shock. However, their study was limited to the slot passage only, and it did not take into account the plenum chamber. However, the plenum chamber is usually implemented in practical bleed systems, and it will thus be analyzed in the present paper. Aerodynamic thermal loads on plenum surfaces are caused by impingement of under-expanded jet, but the detail remains unclear. Under-expanded impingement jet can lead to a high heat transfer rate on the impinged surface, which would become severe in fully confined hypersonic bleed slots systems.

Under-expanded supersonic impinging jet has attracted intensive attention of investigators due to the complicated flow structure and high heat transfer rates in the impingement zone. Researches on supersonic jet have been focused on the features of the complex flow, the mechanism of noise production and the heat transfer. The mean flow visualization and properties, including pressure distributions and heat transfer rates, have been studied extensively, as well as the instantaneous flow fields of axisymmetric or two-dimensional impinging jets [16-18]. It was revealed that the jet impingement essentially depends on the following parameters, the ratio of total pressure and ambient pressure $P_{0} / p_{a}$, the jet-to-plate distance (impingement distance) and impingement angle $\theta$. The jet is said to be moderately under-expanded until a Mach disk forms. Otherwise, it is used to be denoted as a highly under-expanded jet [16]. Most studies concentrated on perpendicular and moderately under-expanded jet impingement. Donaldson and Snedeker [16] noted that the impinging flow field can be generally divided into three regions, i.e., a primary jet flow region upstream the strong interaction areas of impingement, an impingement region, and a wall jet region. Especially in the impingement region, there occur maximum heat transfer rates and the most complex flow patterns with several interacting shock waves, and sometimes a stagnation bubble [19]. Henderson et al. [20] experimentally investigated the transient flow field of a supersonic impinging jet. Their results show clearly that a slip line separates the stagnation bubble and the outer flow. Yusuke et al. [21] further investigated the jet impingement on an inclined flat and classified the flow structure into three types for various impingement angles $\theta$, jet-to-plate distances and flow conditions. The complex flow structure under various geometric conditions also complicate the features of heat transfer rates on the impingement wall. The heat transfer rate distribution along the impinged surface generally exhibits two local peaks in the lateral direction at a modest jet-to-plate distance. When there is no stagnation bubble, the inner one appears at the central point while the outer one occurs as an annular peak at $R / D \approx \pm 2$ due to the increased turbulent energy arising from boundary layer transition in the wall jet region [22-25]. However, when there is a stagnation bubble in the impingement region, the inner peak at the stagnation point disappears while an annular peak occurs at about $R / D \leq 1[22,23]$. It seems that this annular peak takes place because of the impingement of the slip line on the flat plate [20,22]. When the under-expanded jet impinges on an inclined flat plate, the flow characteristics change a lot $[21,26]$. The heat transfer rate distributions along the impingement wall become totally different, which can be attributed to quite a different mechanism. Crafton et al. [27] studied the inclined sonic jet impingement and observed two maximum heat transfer coefficients on the impingement wall. They noted that the maximum heat transfer coefficient decreased as the jet-to-plate distance increased or the impingement angle increased. Song et al. [28] also studied the thermal characteristics of an inclined plate and the energy separation caused by the "vortex effect' from shock-induced phenomena. They obtained the pattern of recovery factor and observed that the low recovery factor region moved downstream and the overall cooling/heating effect declined generally as the impingement angle increased.

Although an in-depth understanding has been achieved regarding the impinging jet flow, the aforementioned works mainly focus on the unconfined jet impingement. However, in the bleed plenum, the impingement jet flow characteristics would be much different due to the geometric confinement. The entrainment of surrounding fluid is prevented and the flow patterns are altered significantly. Few researchers were devoted to the study of confined supersonic 
impinging jets. To the authors' knowledge, only Alvi et al. [29] and Krothapaili et al. [30] and Behnia et al. [31] investigated the jets with confined plates at jet level for various pressure ratios and jet-to-plate distances. However, as for fully confined underexpanded impinging jet with outflow limit, no published reports are found except a subsonic case [32]. It is necessary to investigate the flow patterns and the associated aerodynamic thermal loads for a fully confined under-expanded supersonic impinging jet. In the present study, the fully confined impinging jet means that the supersonic jet impinges into a rectangular plenum with a unique exit on one side. The present numerical results show remarkable differences in both flow structures and aerodynamic thermal loads in the plenum as compared with the case of unconfined impinging jets. It provides a basic conceptual insight for designs in engineering applications.

\section{Numerical method and computational details}

\subsection{Numerical methods}

The steady-state Reynolds averaged Navier-Stokes equations are solved for two-dimensional turbulence flow by using commercial code CFD++. The turbulence model of $k-\omega$ Shear-Stress Transport (SST) is employed to enclose the governing equations with a compressibility correction for high Mach number flows [15,33-35]. The corresponding turbulence kinetic energy transport equation for $k-\omega$ SST model [36] is

$\frac{\partial}{\partial t}(\rho k)+\frac{\partial}{\partial x_{i}}\left(\rho u_{i} k\right)=\hat{P}_{k}-\beta^{*} \rho k \omega+\nabla \cdot\left[\left(\mu+\sigma_{k} \mu_{T}\right) \nabla k\right]$

And the turbulence inverse time-scale transport equation is

$$
\begin{aligned}
\frac{\partial}{\partial t}(\rho \omega)+\frac{\partial}{\partial x_{i}}\left(\rho u_{i} \omega\right)= & \frac{\gamma}{\hat{v}_{T}} P_{k}-\beta \rho \omega^{2}+\nabla \cdot\left[\left(\mu+\sigma_{\omega} \mu_{T}\right) \nabla \omega\right] \\
& +2\left(1-F_{1}\right) \frac{\rho \sigma_{\omega 2}}{\omega} \nabla k \cdot \nabla \omega
\end{aligned}
$$

where the turbulence generation term, limited generation, and limited eddy viscosity are listed as follows.

$P_{k}=\left[\mu_{T}\left(\frac{\partial u_{i}}{\partial x_{j}}+\frac{\partial u_{j}}{\partial x_{i}}+\frac{2}{3} \frac{\partial u_{k}}{\partial x_{k}} \delta_{i j}\right)-\frac{2}{3} \rho k \omega \delta_{i j}\right] \frac{\partial u_{i}}{\partial x_{j}}$

$\hat{P}_{k}=\min \left(P_{k}, 10 \beta^{*} \rho k \omega\right)$

$\hat{v}_{T}=\max \left(v_{T}, 10^{-8}\right) \frac{a_{1} k}{\max \left(a_{1} \omega, S F_{2}\right)}$

The blending functions $F_{1}$ and $F_{2}$ are given by,
Table 1

Model constants for $\Phi_{1}$ and $\Phi_{2}$.

\begin{tabular}{lllllllll}
\hline$\beta_{1}$ & $\beta_{2}$ & $\beta^{*}$ & $\sigma_{k 1}$ & $\sigma_{k 2}$ & $\sigma_{\omega 1}$ & $\sigma_{\omega 2}$ & $a_{1}$ & $\kappa$ \\
\hline 0.075 & 0.0828 & 0.09 & 0.85 & 1.0 & 0.5 & 0.856 & 0.31 & 0.41 \\
\hline
\end{tabular}

$F_{1}=\tanh \left\{\left[\min \left(\max \left(\frac{\sqrt{k}}{\beta^{*} \omega y}, \frac{500 v}{y^{2}}\right), \frac{4 \rho \sigma_{\omega 2} k}{C D_{k \omega} y^{2}}\right)\right]^{4}\right\}$

$F_{2}=\tanh \left\{\left[\max \left(\frac{2 \sqrt{k}}{\beta^{*} \omega y}, \frac{500 v}{y^{2} \omega}\right)\right]^{2}\right\}$

with

$C D_{k \omega}=\max \left(2 \rho \sigma_{\omega 2} \frac{1}{\omega} \nabla k \cdot \nabla \omega, 10^{-10}\right)$

Blending constant is defined as

$\phi=\phi_{1} F_{1}+\phi_{2}\left(1-F_{1}\right)$

The model constants for $\Phi_{1}$ and $\Phi_{2}$ are listed in Table 1 . Noted that, the parameters in the above equations are not noted in the nomenclature section. More detailed information about these parameters can be found in [36] by Menter. Constant $\gamma$ is obtained from the equation below.

$\gamma_{n}=\frac{\beta_{n}}{\beta^{*}}-\frac{\sigma_{\omega n} \kappa^{2}}{\sqrt{\beta^{*}}}, \quad n=1,2$.

In present numerical simulations, compressible perfect gas with compositions of standard air is assumed. The numerical flux through each cell face is evaluated using a second-order Total Variation Diminishing (TVD) scheme based on an approximate Riemann solver named Harten-Lax-van Leer contact (HLLC). The HLLC scheme can exactly resolve isolated shock and slip line while maintaining positively conservative. The minmod limiter is employed to suppress spurious oscillations near the discontinuities while a high-order accuracy is retained away from the jumps.

\subsection{Validations}

Fig. 1a shows an interaction of a straight oblique shock with a bow shock in front of a cylindrical body. Our previous studies have verified that the adopted numerical algorithm is credible and can efficiently resolve high Mach number flows and aerodynamic heating [34]. Edney type IV shock interference includes a jet impingement into the body wall and shock wave/boundary layer interactions [15,33-35]. Fig. 1b and Fig. 1c show that the simulation results are in good agreement with relevant experiment data [37].

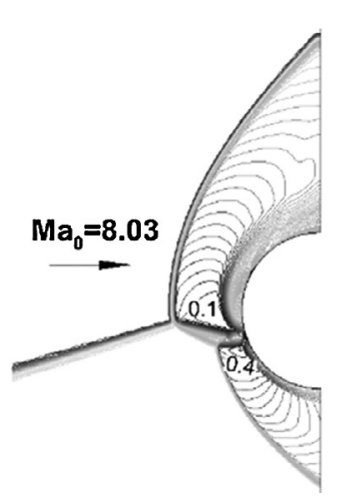

(a) Mach Contours

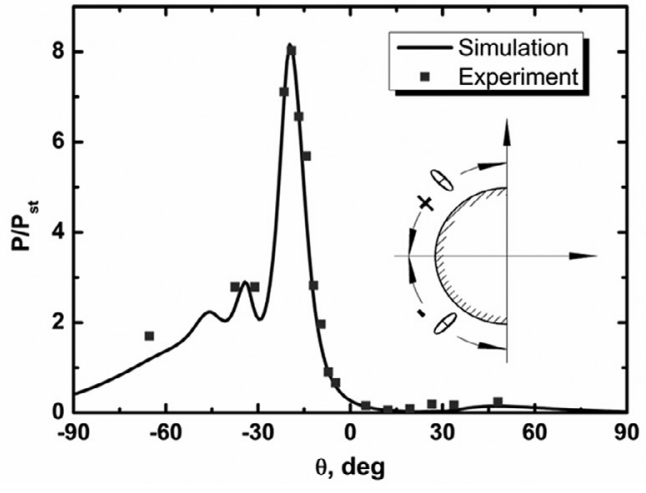

(b) Pressure distribution

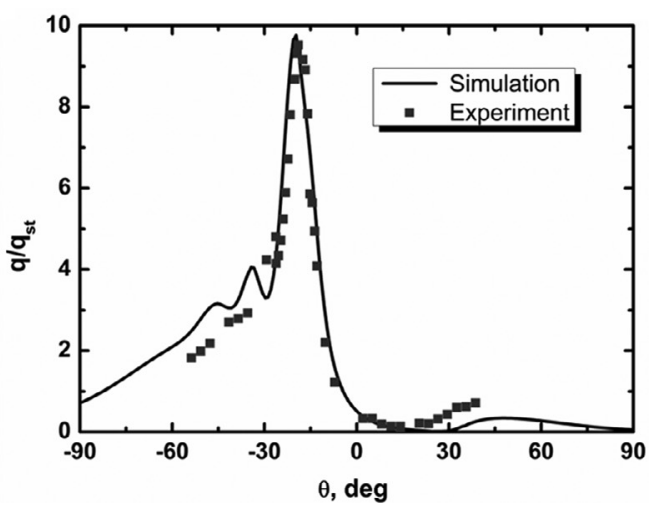

(c) Heat flux distribution

Fig. 1. Comparison between CFD and experimental results for an Edney IV shock pattern [34,37]. 

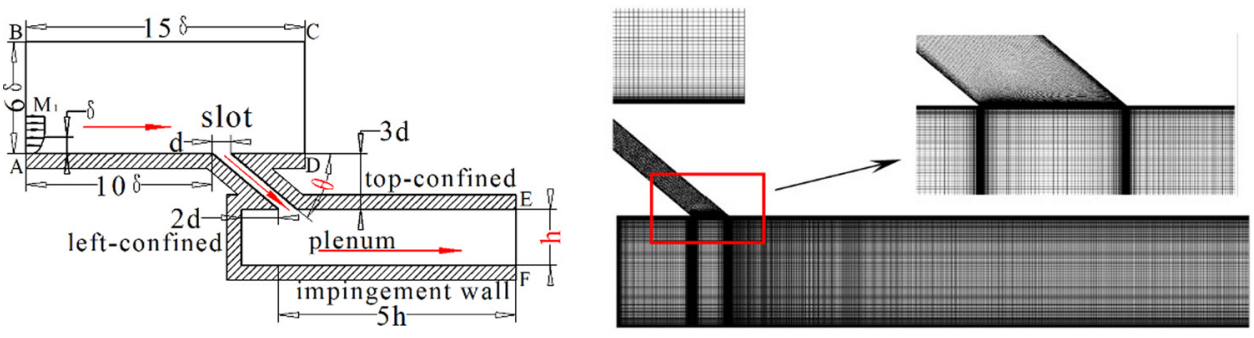

Fig. 2. (a) Computational domain, (b) grid mesh distribution.

Table 2

Free stream conditions at the inflow boundary and solid wall condition.

\begin{tabular}{lllll}
\hline$M_{1}$ & $T_{0}(\mathrm{~K})$ & $p_{1}(\mathrm{~Pa})$ & $\operatorname{Re}\left(\mathrm{m}^{-1}\right)$ & $T_{w}(\mathrm{~K})$ \\
\hline 4 & 1824.5 & 22755 & $1.071 \times 10^{6}$ & 300
\end{tabular}

\subsection{Computational details and grid convergence}

Fig. 2a shows the solution domain used in our two-dimensional simulations. It includes three regions, a region above the plate, a bleed slot and a plenum. The conjunction of two walls is simply a sharp corner. At the inflow boundary $\mathrm{AB}$, high enthalpy freestream airflow conditions are imposed as listed in Table 2, which approximately corresponds to the flow conditions in the internal contraction section of hypersonic inlets operating at flight Mach number of 6 and altitude of $26 \mathrm{~km}$ [15]. Bleed systems are usually installed around this section $[6,7,38]$. The inflow boundary $A B$ has a turbulent boundary layer with a stream-wise velocity profile, where the boundary layer thickness $\delta$ is $2.5 \mathrm{~mm}$. The generated boundary layer profile is based on Musker formulation [39] in conjunction with a compressibility transformation and temperature fit due to Van Driest. The bleed slot opening is kept at a fixed value $d=\delta$. Three percent $(3 \%)$ turbulence level is considered to be appropriate at this entrance. At the outflow boundary $C D$, since it is mostly supersonic flow except for a small region next to the solid wall, all flow parameters are extrapolated from the interior region. At the plenum outflow boundary EF, a back pressure boundary which allows reversed flow is applied. At all solid surfaces, no-slip isothermal temperature conditions are imposed, where $T_{w}=300 \mathrm{~K}$.

Theoretically, convergence is achieved when the residuals of all variables become zero. In CFD++, the residuals for each equation are the average of this quantity over all cells for each equation. In the present case, the convergence criteria are 8 orders of magnitude drop in residual over whole calculation history, in agreement with numerical standards.

Quadrilateral structured cells are used in the simulation as shown in Fig. 2b. The grids are refined near the walls with grid stretching applied in the normal direction near the solid walls so that the first mesh size normal to the wall is $1 \mu \mathrm{m}$, corresponding to $y^{+}<1$ on the solid surface. The grid number in the turbulent boundary layer is greater than 50 to resolve the temperature gradient satisfactorily. In order to capture the detailed flow pattern in the plenum, the plenum region meshes densely. Three different grids $(150 \times 500)$, $(200 \times 792)$ and $(250 \times 880)$ in the plenum region are used in the calculation in order to check the dependence of the solutions on the grid. The convergence of the local Stanton number distributions at the impingement wall with grid refinement is shown in Fig. 3. It is noted that the predictions do not change significantly beyond the $200 \times 792$ mesh. The maximum cell dimension in length corresponds to $0.1 \mathrm{~mm}$ or less. Thus a $200 \times 792$ mesh is adequate for this flow configurations and all subsequent calculations are performed using this mesh resolution. The total number of grid cells of all calculations is between 0.18 and 0.25 million.

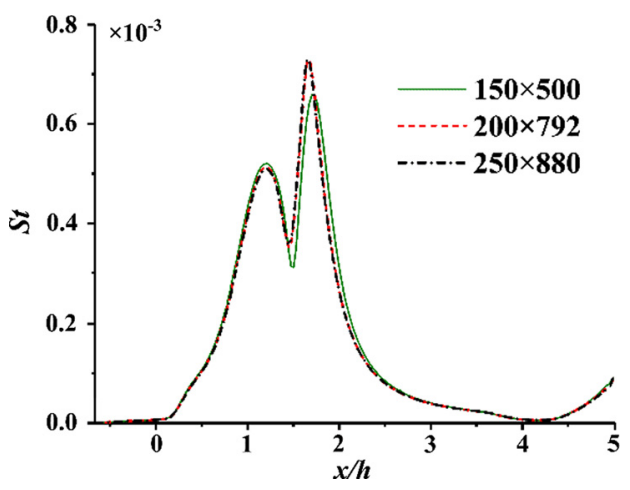

Fig. 3. Grid refinement analysis for the plenum region with $h / d=3, \theta=40^{\circ}$.

\section{Numerical results and discussion}

The flow patterns and aerodynamic thermal loads on the solid wall of plenum are discussed in the present section for various geometric configurations and various back pressure ratios. The slot angle (impingement angle) is changed from $30^{\circ}$ to $70^{\circ}$ at 10 degree intervals. In this paper, the nominal jet-to-plate distance ratio $h / d=2,3,6$ are selected. The back pressure ratio is set to vary from 0.09 to 1.63 . Detailed flow patterns and aerodynamic thermal loads within the bleed slot region were studied by Yue et al. [15]. The present works will pay much attention to the plenum region.

In the following discussions, the local heat flux rates are denoted in terms of Stanton number $(S t)$ defined as:

$S t=\frac{q_{w}}{\rho_{1} U_{1} C_{p}\left(T_{0}-T_{w}\right)}$

where $q_{w}, \rho_{1}, U_{1}, C_{p}, T_{0}$ denoted the local heat flux on the solid surface, freestream density, freestream velocity, local specific heat, total temperature, and wall temperature, respectively.

\subsection{Effects of slot angle on aerodynamic thermal loads}

Numerical results provide a detailed description of the flow structures of a fully confined supersonic impinging jet. Fig. 4 shows the Mach contour maps in the plenum region for different slot angles, where $h / d=3$ and the back pressure of the exit of plenum is temporarily presumed to have no influence on the upstream flow, which will be discussed in section 3.3. For the convenience of descriptions, Fig. 5 shows a schematic of the flow structure in the plenum region at $\theta=30^{\circ}$.

As shown in Fig. 5, a supersonic jet occurs in the plenum and expands downstream of the slot exit. A plate shock wave is generated because of the blockage of the impingement wall, leading to a recirculation region $\mathrm{B} 1$ on the top-confined wall of the plenum. A jet shock is generated by the obstruction of separation B1 and interacts with the impingement wall boundary layer to induce a small separation bubble B2. For a free jet, a barrel shock always occurs surrounding the jet core, as indicated in Fig. 6 [21]. However, in the present fully confined case, no jet shock occurs on the 

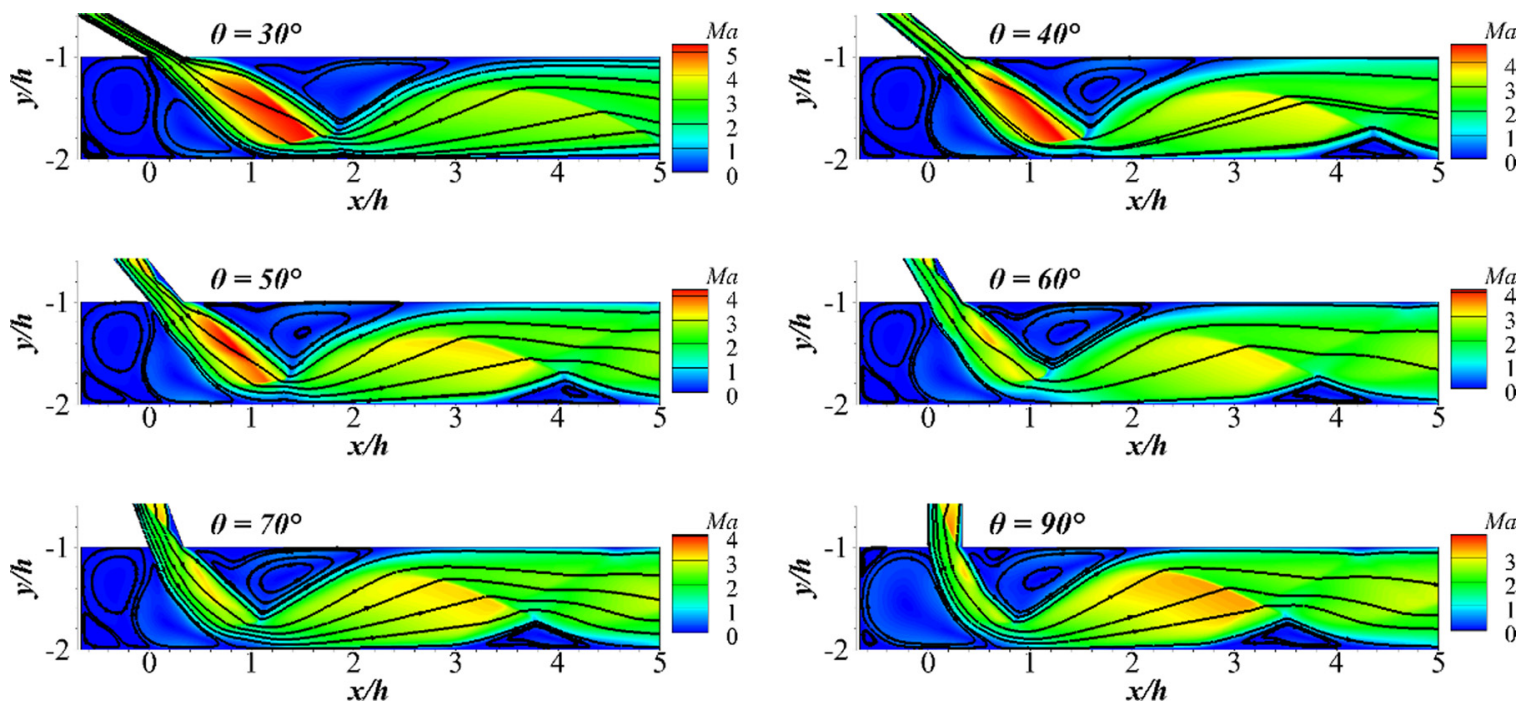

Fig. 4. Mach contours on the plenum at various slot angles. (For interpretation of the colors in the figure(s), the reader is referred to the web version of this article.)
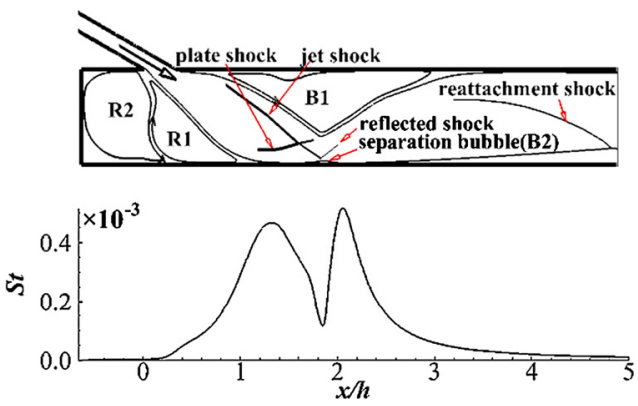

Fig. 5. Schematic of flow structures and Stanton number distributions along the impingement wall for the slot angle of $30^{\circ}$

left side of the jet core because of adaptive matching of the pressure in the left recirculation region. Therefore, the jet shear layer can directly impinge the wall.

As the slot angle increases, the separation bubble B1 moves leftward and extends to the jet slot exit at $\theta=60^{\circ}$. As a result, the striking point of the jet shock on the impingement wall moves leftward as the slot angle $\theta$ increases and gets closer to the impingement region of the jet shear layer. Meanwhile, the jet shock becomes weaker and finally unrecognizable at $\theta=70^{\circ}$. Because of these separation bubbles resulting from the fully confined configuration, the flow patterns are much different from the free impinging jet structures. As implied in [21] by Yusuke, the larger slot angle $\theta$ triggers a Mach reflection between the plate shock and the jet shock, as demonstrated in Fig. 6b. In the present fully confined case, the Mach reflection does not occur at $h / d=3$ due to the weakening of plate shock and jet shock. In addition, as the slot angle $\theta$ increases, the left side two recirculation regions with opposite directions merge into one, and the high-speed rotational fluid directly impinges the left-confined wall, as shown in Fig. 4 at $\theta=90^{\circ}$.

The Stanton number distributions along the impinged surface at $\theta=30^{\circ}$ are shown in Fig. 5. There are two peaks of Stanton number on the impingement wall. There exist two different causes, i.e. the high turbulence level and the shock wave/boundary layer interactions, either can lead to a local peak of heat transfer. In the present case, the left peak locates in the impingement region of the jet shear layer, which comes from the high level of turbulence. The right peak is attributed to the jet shock/boundary layer interactions (SWBLIs), which always results in high thermal loads.

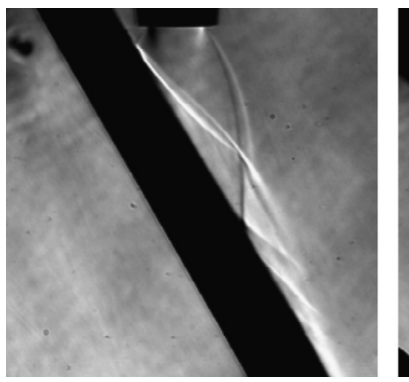

(a) $\theta=30^{\circ}, h / d=2.0$

Fig. 6. Schlieren images at various plate angles $[21]\left(P_{0} / p_{a}=7.0\right)$.

Table 3

Values of peak St and the maximum St on the impingement wall.

\begin{tabular}{lllllll}
\hline$\theta$ & $30^{\circ}$ & $40^{\circ}$ & $50^{\circ}$ & $60^{\circ}$ & $70^{\circ}$ & $90^{\circ}$ \\
\hline Left peak St $\left(\times 10^{-3}\right)$ & 0.47 & 0.51 & 0.49 & 0.51 & - & - \\
Right peak St $\left(\times 10^{-3}\right)$ & 0.52 & 0.73 & 0.66 & 0.64 & - & - \\
Maximum St $\left(\times 10^{-3}\right)$ & 0.52 & 0.73 & 0.66 & 0.64 & 0.61 & 0.65 \\
\hline
\end{tabular}

The Stanton number distributions along the impingement wall at various slot angles are presented in Fig. 7. For $\theta=30^{\circ}, 40^{\circ}$, $50^{\circ}, 60^{\circ}$, the oblique impinging jet generates two peaks on the impingement wall as listed in Table 3 . The left peaks remain nearly unchanged, while the value of right peaks associated with SWBLIs increases initially and then decreases. As $\theta$ increases, the impinging point of the jet shock moves upstream, getting closer to the high turbulence level impingement region of the shear layer [22], as shown in Fig. 8. This is in favor of the increase in heat transfer rate. Therefore, the right peak Stanton number increases first. However, as the impingement angle further increases, the jet shock becomes weaker, resulting in a decrease of Stanton number. Compared to the left peak, the right peak is always larger. For $\theta=70^{\circ}$ and $90^{\circ}$, only one peak appears on the impingement wall because of the disappearance of the jet shock. The maximum Stanton numbers are 0.00061 and 0.00065 , respectively. In general, the global peak changes a little when $\theta>50^{\circ}$.

The Stanton number distributions along the top-confined wall are shown in Fig. 9 for four slot angles. Except for the vicinity of slot exit, the local maximum Stanton number appears at the reattachment location of the recirculation region $\mathrm{B} 1$. The values of these local peaks are listed in Table 4. They are less than half 

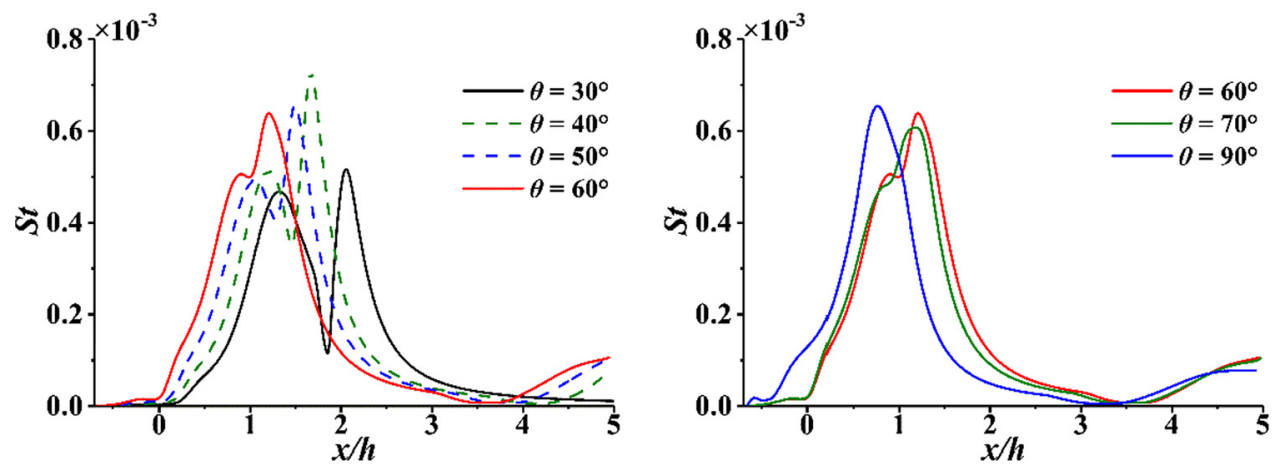

Fig. 7. Stanton number distributions on the impinging wall at various slot angles.
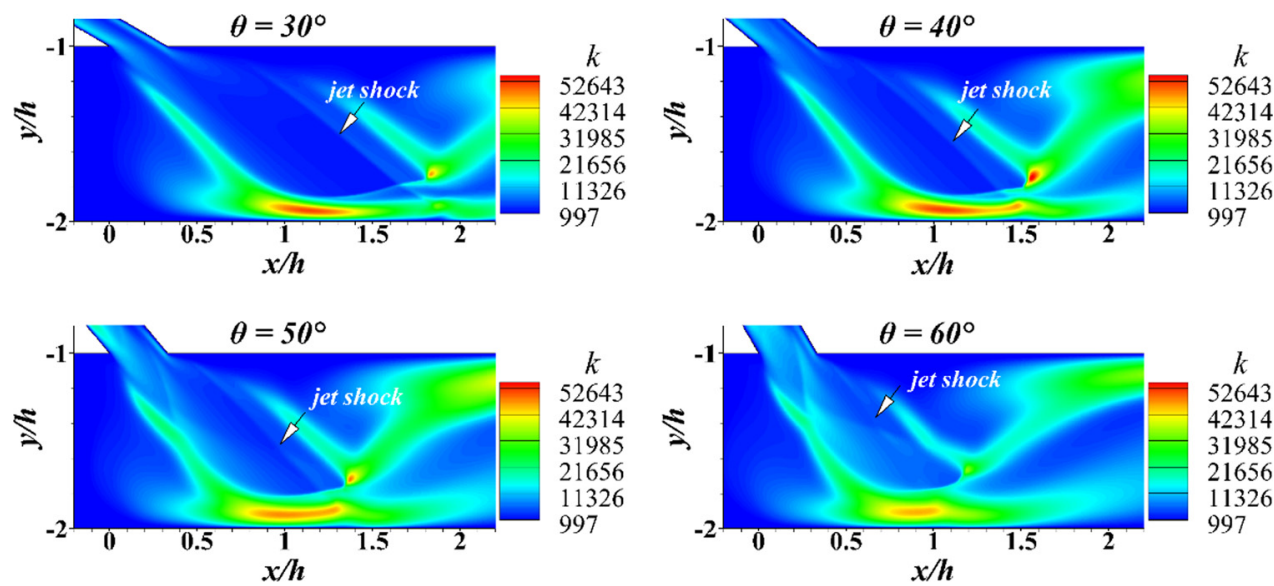

Fig. 8. Turbulence kinetic energy contour at $\theta=30^{\circ}, 40^{\circ}, 50^{\circ}, 60^{\circ}$.

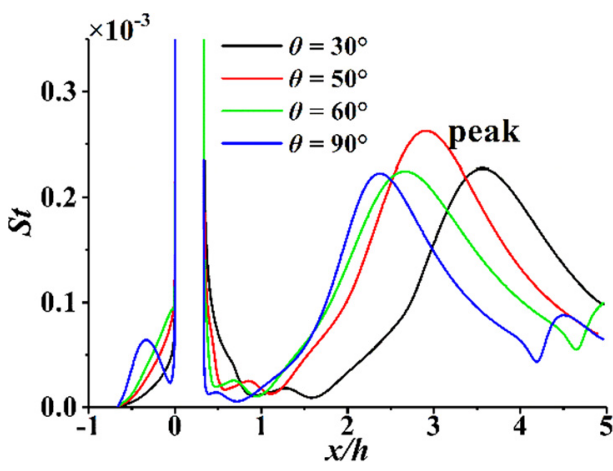

Fig. 9. Stanton number distributions on the top-confined wall at various slot angles.

Table 4

Values of the local peak St on the top-confined wall.

\begin{tabular}{lllllll}
\hline$\theta$ & $30^{\circ}$ & $40^{\circ}$ & $50^{\circ}$ & $60^{\circ}$ & $70^{\circ}$ & $90^{\circ}$ \\
\hline Maximum St $\left(\times 10^{-3}\right)$ & 0.227 & 0.252 & 0.263 & 0.224 & 0.249 & 0.223 \\
\hline
\end{tabular}

of the peaks on the impingement wall for the corresponding impingement angles. Near the slot exit, however, there is always a high thermal load area due to the sharp corner. It is known that a smaller blunted radius results in a higher heat flux in high speed and high-temperature flows [40]. In the present simulations, the corner is sharp because this region is not the main concern of this paper, and a sharp corner is convenient for the mesh generation and the simulation. Extra simulations of blunted corners showed that the extremely large Stanton number would reduce to less than 0.0004 when the corner is rounded to a radius of 2 millimeters.

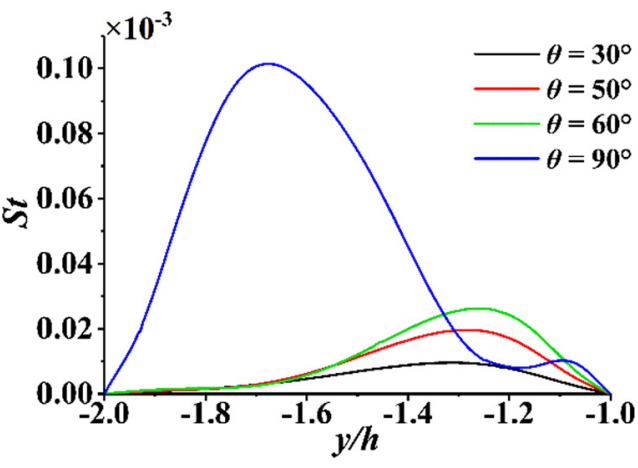

Fig. 10. Stanton number distributions on the left-confined wall for various slot angles.

Fig. 10 shows the Stanton number distributions along the leftconfined wall. When $\theta<90^{\circ}$, the maximum Stanton number remains no more than 3 percent of the peaks on the impingement wall because of the low speed flow in this region. At $\theta=90^{\circ}$, the peak Stanton number dramatically rises to 16 percent due to the merging of two recirculation regions, as shown in Fig. 4. Therefore, the extension of the left side is beneficial for the formation of two recirculation regions to separate the relatively high-speed flow from the left side wall.

The walls of the bleed slot also suffer severe thermal loads, which has been studied by Yue et al. [15]. The Mach contour in the bleed slot region is shown in Fig. 11. The local maximum Stanton number is displayed in Fig. 12. This peak also locates at the reattachment point of a separation bubble, as shown in Fig. 11. Compared to the maximum Stanton number on the impingement wall, the maximum Stanton number on the upstream slot wall is 


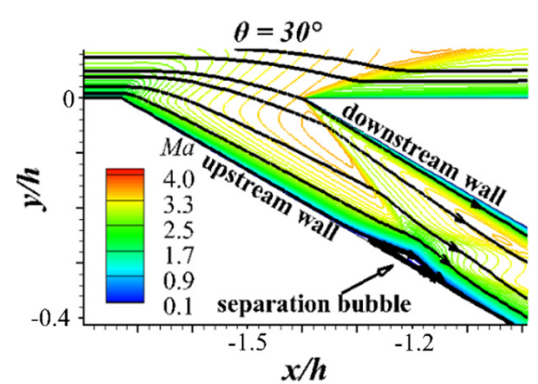

Fig. 11. Mach number contour in the bleed slot.

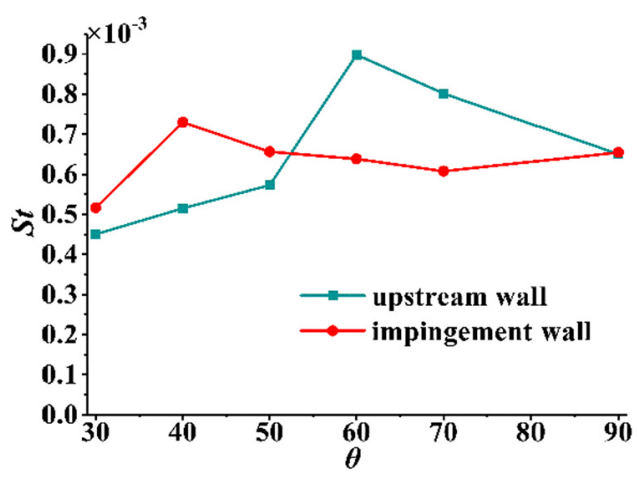

Fig. 12. Comparison of maximum Stanton numbers on the upstream wall and on the impinging wall.
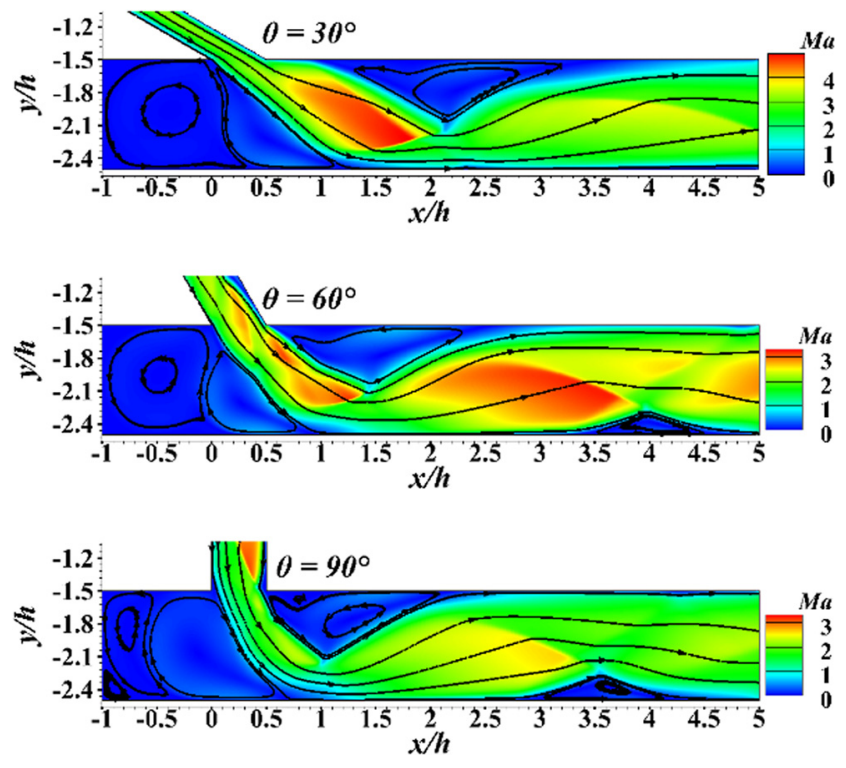

Fig. 13. Mach number contours at various slot angles for $h / d=2$.

lower when $\theta<60^{\circ}$, while this tendency reverses as the slot angle further increases, as shown in Fig. 12.

\subsection{Effects of plenum height}

To further investigate the effects of plenum height on aerodynamic thermal loads, three typical slot angles $\theta=30^{\circ}, 60^{\circ}$, and $90^{\circ}$, with the ratio of $h / d=2,3,6$ are selected. Fig. 13 and Fig. 14 show the Mach contour at different slot angles with $h / d=2,6$. Overall, the flow patterns change a little as $h / d$ increases. The flow characteristics for $h / d=2$ are similar to those for $h / d=3$.

As the plenum height increases, the main flow structures remain unchanged except for $\theta=60^{\circ}, h / d=6$. As shown in Fig. 15, a Mach stem structure appears due to the large $h / d$. It is similar
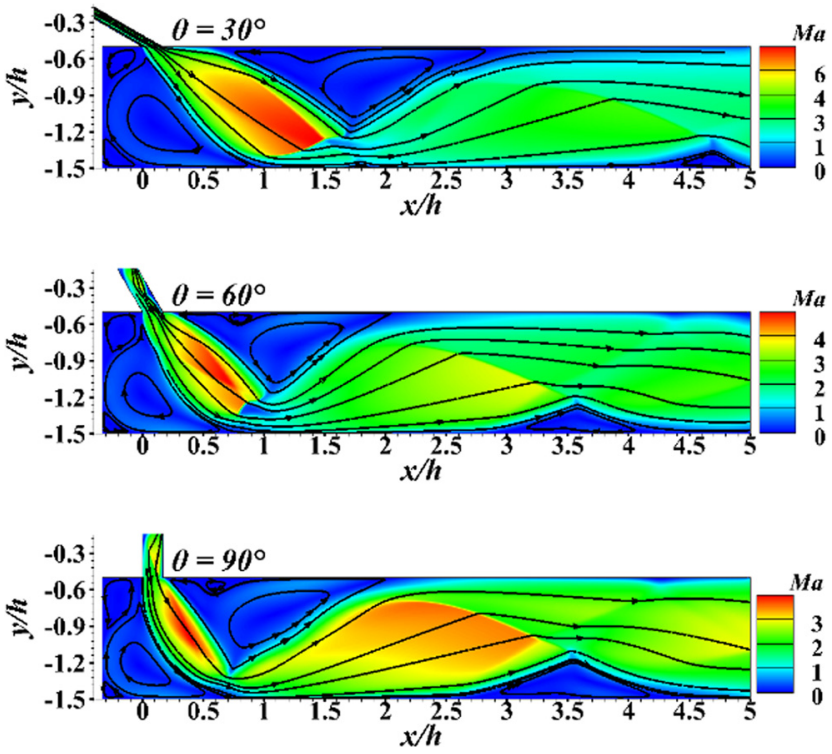

Fig. 14. Mach number contours at various slot angles for $h / d=6$.

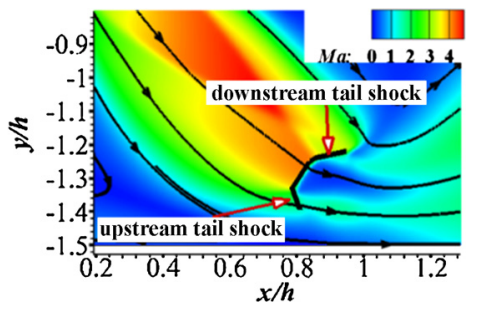

Fig. 15. Shock wave structures in core flow region for $\theta=60^{\circ}, h / d=6$.

to the cell structures of the under-expanded free jet. For a highly under-expanded free jet, a Mach disk forms within the shock cell structure [16,21]. Another feature is the formation of over-under structure of two recirculation regions on the left side at $h / d=6$ instead of a left-right structure at $h / d=3$. It will cause impingement of a high speed flow on the left-confined wall. Meanwhile, the maximum Stanton number will increase a bit. Extension of the left side can convert the formation of over-under separation bubbles into a left-right structure.

Fig. 16 shows the Stanton number distributions on the impingement wall. Generally, the maximum Stanton number shows a decreasing trend with $h / d$ for different impingement angles. It is consistent with Goldstein's and Crafton's results for the free jet impingement [27]. At $\theta=30^{\circ}$, two peaks still remain in Stanton number distribution. The left peak Stanton number shows a decreasing trend with impingement distance but the right peak does not. At $\theta=60^{\circ}, h / d=6$, as shown in Fig. $16 \mathrm{~b}$, the interaction between the upstream tail shock of Mach stem and the boundary layer contributes to the peak Stanton number. At other $h / d$, the maximum Stanton number is attributed to the jet shock rather than to the upstream tail shock.

For different impingement distances, the distribution profile of Stanton number on the top-confined wall is similar to the case of $h / d=3$ shown in Fig. 9. The local maximum Stanton number on the top-confined wall relative to that on the impingement wall is listed in Table 5. It indicates a decreasing trend with impingement distance for each different impingement angle. It also reveals that it is worth paying attention to the high thermal loads on the topconfined wall for short impingement distance. 


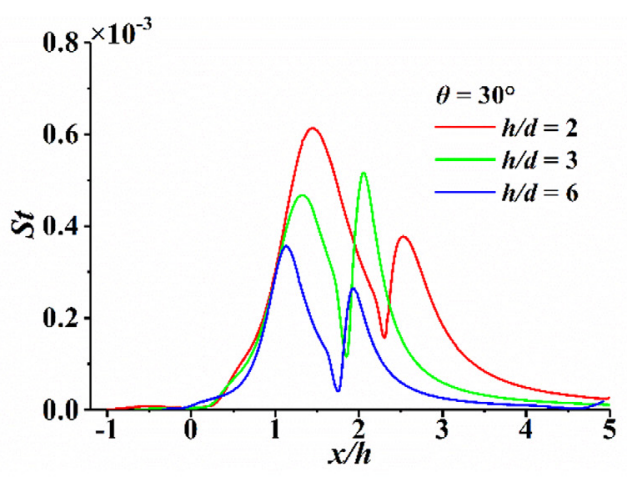

(a) $\theta=30^{\circ}$

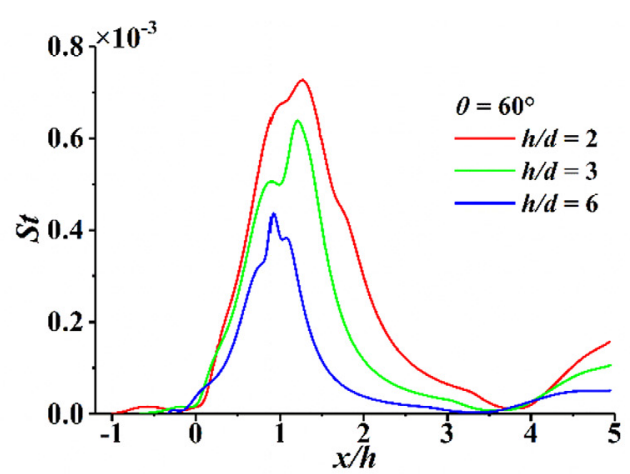

(b) $\theta=60^{\circ}$

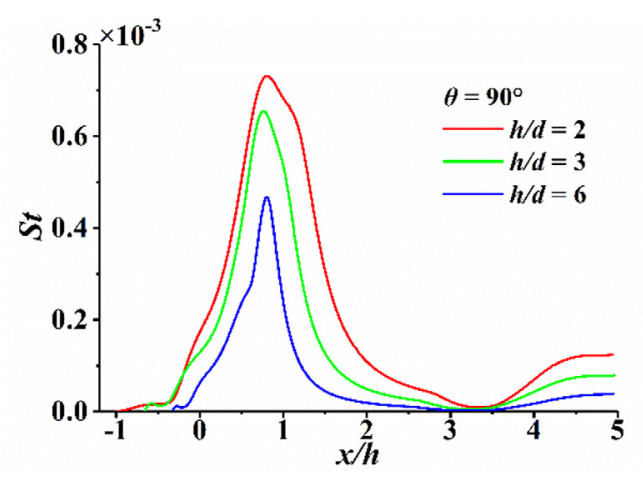

(c) $\theta=90^{\circ}$

Fig. 16. Stanton number distributions on the impinging wall for various slot angles and $h / d$.

Table 5

Maximum Stanton number on the top-confined wall relative to the maximum on the impingement wall.

\begin{tabular}{llll}
\hline$h / d / \theta$ & $30^{\circ}$ & $60^{\circ}$ & $90^{\circ}$ \\
\hline 2 & $49.78 \%$ & $46.96 \%$ & $41.70 \%$ \\
3 & $43.65 \%$ & $35.00 \%$ & $34.31 \%$ \\
6 & $34.00 \%$ & $30.27 \%$ & $25.87 \%$ \\
\hline
\end{tabular}

\subsection{Effects of choke condition of the plenum exit}

In the aforementioned discussions, an extrapolation boundary condition is imposed on the plenum exit, which leaves out the consideration of the effect of back pressure on the plenum outlet. In practical inlet bleed systems, a geometrical throat is generally designed downstream the plenum to choke the flow, in which a high energy stream exhausts through a supersonic nozzle to make up the thrust losses arising from the bleed mass loss. To minimize the bleed drag, the plenum pressure should be designed as high as possible [41]. Flow fields and thermal loads for various back pressure conditions are thus surveyed hereafter. The back pressure ratio, $p r=p_{b} / p_{i}$, imposed on the plenum exit is in the range of 0.09-1.63, which do not affect the flow in the entrance of bleed slot.

The present discussions are based on the case of $h / d=3$ and $\theta=30^{\circ}$. Fig. 17 displays the Mach contours for four different back pressures. Obviously, increasing back pressure has a great impact on the flow structure. At $p r=0.09$, the back pressure induces a large separation region B3 on the impingement wall, as shown in Fig. 17b. An associated separated shock wave occurs and strikes the boundary layer on the top-confined wall, resulting in a thickening of the boundary layer. Further increasing back pressure enlarges the separation region B3. It makes the striking point of associated separation shock move upstream. As a result, the separation region B1 becomes larger, as shown in Fig. 17c. As pr increases to
0.4 , the plate shock becomes very weak. The impinging region flow can still persist despite the adverse pressure gradient in separation region B3 but the flow near the top-confined wall cannot. Thus a large separation region appears and a wall jet flow takes form, as shown in Fig. $17 \mathrm{~d}$. The back pressure at the plenum exit can directly affect the jet flow through the large scale separation. The increased back pressure reduces the expansion magnitude of the jet flow. As the $p r$ further increases to 0.48 , the slot jet becomes of over-expanded type rather than under-expanded type. The jet flow speed gradually decreases as $p r$ increases. As $p r$ increases to 0.7 , the supersonic region on the plenum is divided into two parts as displayed in Fig. 17e. The classical shock train structure occurs with an upstream background shock wave in the internal flows [42]. And a subsonic flow takes form in the core flow region near the impingement wall. Finally, further increasing back pressure would make the shock train move upstream and reduce the jet flow speed inside the plenum to subsonic.

The Stanton number distributions along the impingement wall are shown in Fig. 18 for four typical back pressures. The most notable feature is the high thermal loads on the impingement region at different back pressure ratios. As the back pressure ratio increases, a remarkable change in Stanton number distributions is the disappearance of the second peak associated with SWBLIs at about $p r=0.13$. As separation region B3 becomes larger, the average magnitude of pressure in separation region B1 increases. Therefore, the striking point of jet shock move leftward and finally overlaps with the high turbulence level impinging region of the jet shear layer. And this would lead to the merging of two peaks. The relationships between the maximum Stanton number and back pressure $p r$ are displayed in Fig. 19, where a peak occurs at $p r \approx 0.7$. As for change of the slope in Fig. 19, the maximum Stanton number increases at two different rates. The inflection point is located at $p r \approx 0.35$. As $p r$ increases from 0.09 to 0.35 , the striking point of the jet shock gets close to the region where 


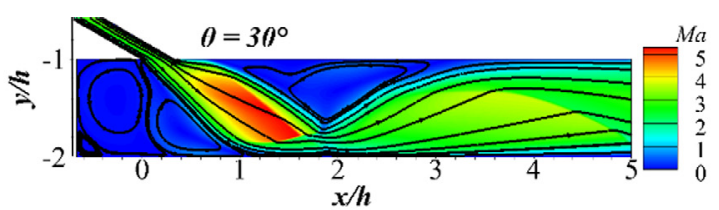

a) Extrapolation boundary condition

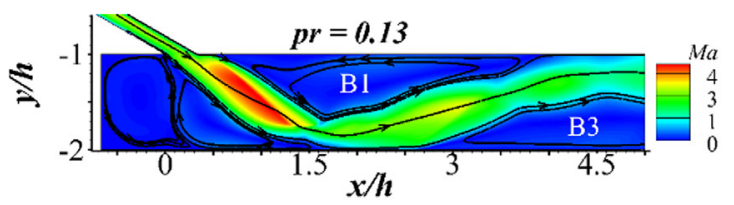

c) $p r=0.13$

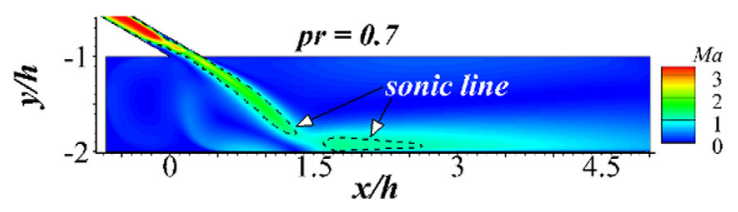

e) $p r=0.7$

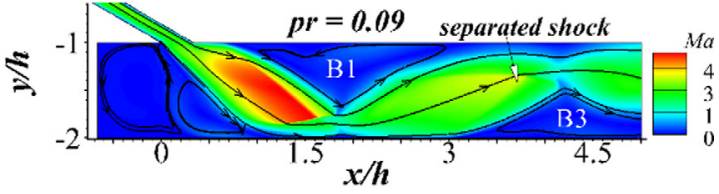

b) $p r=0.09$

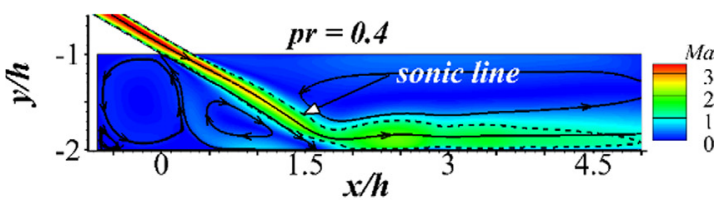

d) $p r=0.4$

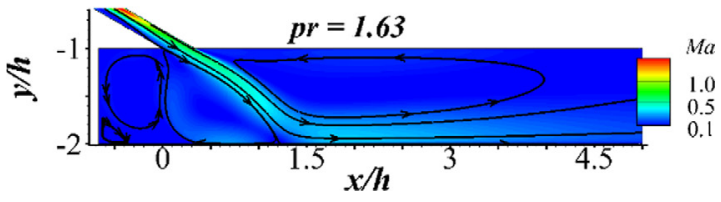

f) $p r=1.63$

Fig. 17. Mach contour map around the plenum region at $\theta=30^{\circ}$ and $h / d=3$ for different back pressures.

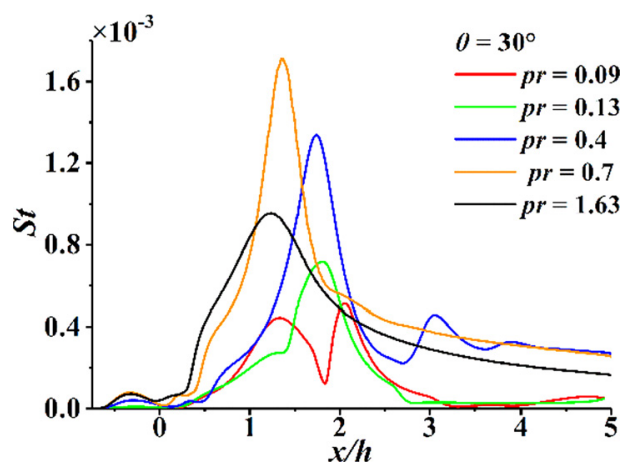

Fig. 18. Stanton number distributions on the impingement wall for four back pressures.

the jet shear layer impinges the impingement wall. These effects contribute to the increase of the maximum Stanton number. As $\mathrm{pr}$ increases from 0.35 to 0.7 , however, the jet shock disappears and the growth of the maximum Stanton number is ascribed to the turbulence diffusion from the jet shear layer [22]. With further increasing $p r$, as discussed above, the shock train in the slot would move upstream, and in turn slow down the jet flow. As a result, the turbulence diffusion entrains more low energy air to impinge the wall, and the jet flow impinges the wall at subsonic speed. And thus the maximum Stanton number turns to decrease, with a peak appearing at $p r \approx 0.7$.

As aforementioned, in order to make up the thrust losses due to bleed mass loss, the plenum pressure should be designed as high as possible. However, as shown in Fig. 20, the flow in the bleed slot region will be affected once the back pressure exceeds a certain threshold. A long and narrow separation region with several vortexes locates next to the upstream slot wall, as shown in Fig. 20b, which is similar to the classical shock train structure with background shock wave in the scramjet isolator [42]. It may give rise to severe thermal loads on the slot wall. The thermal loads along the bleed slot surfaces are shown in Fig. 21. It shows that the Stanton number increases sharply once the downstream pressure exerts influences on the slot flow.

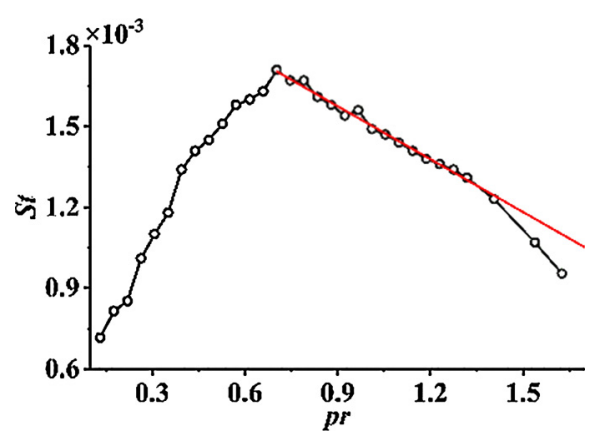

Fig. 19. The relationship between Max Stanton number and back pressure.

In order to understand the effects of back pressure on aerodynamic thermal loads, the maximum Stanton number is normalized as follows for easy comparison:

$\eta=\frac{S t_{\max }}{S t_{\max , u}}$

where $S t_{\max , u}$ is the local maximum Stanton number on upstream slot wall without the influence of downstream flow and $S t_{\max }$ is the maximum Stanton number on different walls at different $p r$.

The normalized maximum Stanton numbers on different walls are displayed versus the back pressure ratio, as shown in Fig. 22. Initially, each wall except for the left-confined wall suffers the same order of thermal load as the slot walls. However, once the downstream plenum flow is choked, the maximum Stanton number on the impingement wall increases to 3 times high. And the top-confined wall suffers even severer thermal loads, as compared with the upstream slot wall. As pr increases to 0.4 , a wall jet flow takes form and the reattachment of recirculation region disappears, and thus the Stanton number drops suddenly. Once the choke affects the slot flow, the maximum Stanton number on the slot walls would also grow rapidly and eventually increases to the same order of magnitude as that of thermal loads on the impingement wall. Therefore, choking the downstream flow to make up the thrust losses will lead to high thermal loads on the impingement wall and slot walls. Here the $p r=0.5$ is recommended to be 


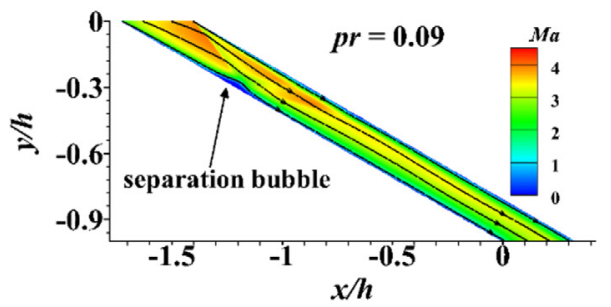

(a) not influenced by downstream flow

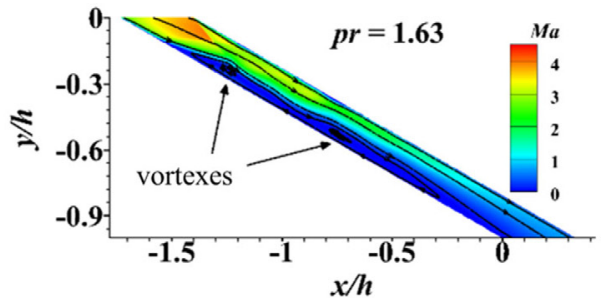

(b) influenced

Fig. 20. Mach number contour in bleed slot region at $\theta=30^{\circ}$.

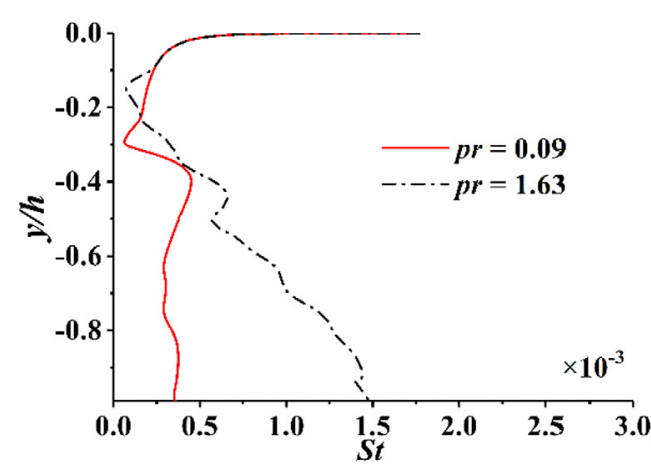

(a) upstream slot wall

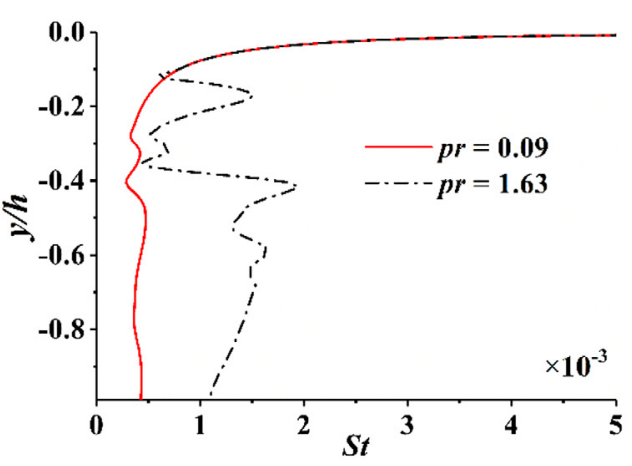

(b) downstream slot wall

Fig. 21. Stanton number distributions.

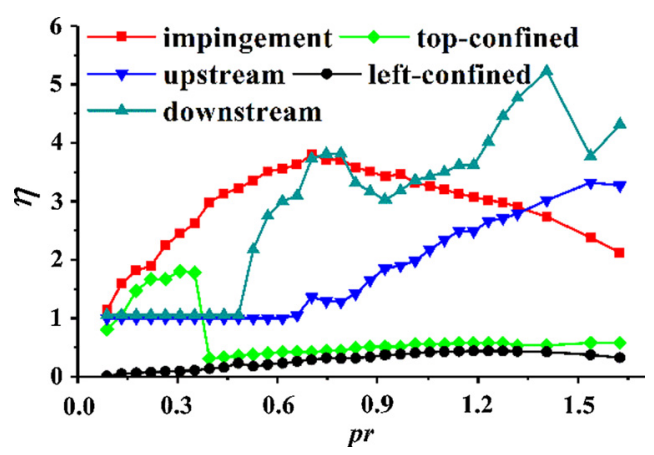

Fig. 22. Maximum Stanton number distributions on different walls at various back pressures.

a design point because the slot flow is not affected at this condition and it is easy to control. Although the impingement wall faces high thermal loads, it can be relieved by heightening the plenum.

\section{Conclusions}

Systematic numerical simulations are conducted to study the heat transfer behaviors of a fully confined slot jet impingement from the bleed systems. Three key factors, i.e., bleed slot angle, impingement distance, and back pressure at the plenum exit are investigated. The Stanton numbers on each wall of the plenum and slot are extensively analyzed.

The flow patterns in the present fully confined conditions differ significantly from the free jet impingement with a barrel shock surrounding. A plate shock wave is generated above the impingement wall and induces a separation region on the top-confined wall. The jet shock then occurs on the right side due to the obstruction of this separation region. On the left side of the jet core, the jet shear layer directly impinges the wall without the occurrence of jet shock because of the self-adaption effect of the recirculation region resulting from the left-confined walls. The jet shear layer and the jet shock contribute to two peaks of Stanton number on the impingement wall. As the slot angle increases, the jet shock weakens and the striking point moves toward the impingement region of the jet shear layer. At a certain angle around $\theta=70^{\circ}$, the jet shock becomes unrecognizable, giving rise to a single peak of Stanton number on the impingement wall. Thus the thermal load characteristics exhibit a complicated variation rule with the slot angle. The plenum height affects not much the flow structure except that a Mach stem structure appears under some particular conditions, but the maximum Stanton number shows a decreasing trend with the impingement distance. As compared with those on the impingement wall, the maximum Stanton numbers on the top-confined wall and the left-confined wall are much smaller.

When the downstream flow of the plenum is choked, the flow patterns change a lot. Large scale separation regions occur and move upstream gradually. The jet shock and plate shock become weaker and finally vanishes as the plenum back pressure increases. But the increased plenum pressure leads to a rapid increase of the maximum Stanton numbers on the plenum walls. A peak appears on the impingement wall at $p r=0.7$, beyond which the jet strikes on the impingement wall at subsonic speed. The maximum Stanton number on the top-confined wall experiences a sudden drop at $p r=0.4$ because the wall jet patterns result in the disappearance of reattached shock. On the impingement wall, the maximum Stanton number generally remains larger than those on the slot walls until the shock train accompanied with large scale separation is pushed inside the slot passage by the high plenum pressure. The back pressure ratio is recommended to be about 0.5 to keep the slot flow unaffected and prevent the slot walls from high thermal loads. To protect the plenum walls, it will be better to heighten the plenum as far as possible.

\section{Conflict of interest statement}

The authors declare that there is no conflict of interests regarding the publication of this article. 


\section{Acknowledgements}

This work is funded by the National Natural Science Foundation of China (Grant Nos. 11672309 and 11472279).

\section{References}

[1] D.W. Riggins, C.R. Mcclinton, P.H. Vitt, Thrust losses in hypersonic engines. Part 1: methodology, J. Propuls. Power 13 (2015) 281-287.

[2] D. Schulte, D. Henckels, U. Wepler, Reduction of shock induced boundary layer separation in hypersonic inlets using bleed, Aerosp. Sci. Technol. 2 (1998) 231-239.

[3] D. Schulte, A. Henckels, R. Neubacher, Manipulation of shock/boundary-layer interactions in hypersonic inlets, J. Propuls. Power 17 (1999) 585-590.

[4] J. Häberle, A. Gülhan, Experimental investigation of a two-dimensional and a three-dimensional scramjet inlet at Mach 7, J. Propuls. Power 24 (2008) 1023-1034.

[5] J. Häberle, A. Gülhan, Internal flowfield investigation of a hypersonic inlet at Mach 6 with bleed, J. Propuls. Power 23 (2015) 1007-1017.

[6] T. Kouchi, T. Mitani, G. Masuya, Numerical simulations in scramjet combustion with boundary-layer bleeding, J. Propuls. Power 21 (2012) 642-649.

[7] T. Mitani, N. Sakuranaka, S. Tomioka, K. Kobayashi, Boundary-layer control in Mach 4 and Mach 6 scramjet engines, J. Propuls. Power 21 (2005) 636-641.

[8] A. Weiss, H. Olivier, Behaviour of a shock train under the influence of boundary-layer suction by a normal slot, Exp. Fluids 52 (2012) 273-287.

[9] M.S.B. Jeffrey, M. Donbar, Graham J. Linn, Simultaneous high-frequency pressure and TDLAS measurements in a small-scale axisymmetric isolator with bleed, in: AIAA Aerospace Sciences Meeting Including the New Horizons Forum and Aerospace Exposition, 2012.

[10] F. Xing, C. Ruan, Y. Huang, X.Y. Fang, Y.F. Yao, Numerical investigation on shock train control and applications in a scramjet engine, Aerosp. Sci. Technol. 60 (2017) 162-171.

[11] Y.B. He, H.Y. Huang, D.R. Yu, Investigation of corner separation and suction control in constant area duct, Aerosp. Sci. Technol. 66 (2017) 70-82.

[12] F. Falempin, M. Goldfeld, Y.V. Semenova, A. Starov, K.Y. Timofeev, Experimental study of different control methods for hypersonic air inlets, Thermophys. Aeromech. 15 (2008) 1-9.

[13] J. Chang, D. Yu, W. Bao, Y. Fan, Y. Shen, Effects of boundary-layers bleeding on unstart/restart characteristics of hypersonic inlets, Aeronaut. J. 113 (2009) 319-327.

[14] S. Pandian, J. Jose, M. Patii, P. Srinivasa, Hypersonic air intake performance improvement through different bleed systems, in: International Symposium, 2001, DTIC Document, p. 31.

[15] L. Yue, H. Lu, X. Xu, X. Chang, Aerothermal characteristics of bleed slot in hypersonic flows, Sci. China, Phys. Mech. Astron. 58 (2015) 1-14.

[16] C.D. Donaldson, R.S. Snedeker, A study of free jet impingement. Part 1. Mean properties of free and impinging jets, J. Fluid Mech. 45 (1971) 281-319.

[17] D. Dosanjh, W. Sheeran, Observations on jet flows from a two-dimensional, underexpanded, sonic nozzle, AIAA J. 6 (1968) 540-542.

[18] F. Alvi, J. Ladd, W. Bower, Experimental and computational investigation of supersonic impinging jets, AIAA J. 40 (2002) 599-609.

[19] G. Kalghatgi, B. Hunt, Occurrence of stagnation bubbles in supersonic jet impingement flows, Aeronaut. Q. 27 (1976) 169-185.
[20] B. Henderson, J. Bridges, M. Wernet, An experimental study of the oscillatory flow structure of tone-producing supersonic impinging jets, J. Fluid Mech. 542 (2005) 115-137.

[21] Y. Nakai, N. Fujimatsu, K. Fujii, Experimental study of underexpanded supersonic jet impingement on an inclined flat plate, AIAA J. 44 (2006) 2691-2699.

[22] M.S. Yu, B.G. Kim, H.H. Cho, Heat transfer on flat surface impinged by an underexpanded sonic jet, J. Thermophys. Heat Transf. 19 (2005) 448-454.

[23] M. Rahimi, I. Owen, J. Mistry, Impingement heat transfer in an under-expanded axisymmetric air jet, Int. J. Heat Mass Transf. 46 (2003) 263-272.

[24] J. Lee, S.J. Lee, Stagnation region heat transfer of a turbulent axisymmetric jet impingement, Exp. Heat Transf. 12 (1999) 137-156.

[25] M. Behnia, S. Parneix, P.A. Durbin, Prediction of heat transfer in an axisymmetric turbulent jet impinging on a flat plate, Int. J. Heat Mass Transf. 41 (1998) 1845-1855.

[26] P. Lamont, B. Hunt, The impingement of underexpanded, axisymmetric jets on perpendicular and inclined flat plates, J. Fluid Mech. 100 (1980) 471-511.

[27] J. Crafton, C. Carter, G. Elliott, J. Sullivan, The impingement of sonic and subsonic jets onto a flat plate at inclined angles, Exp. Fluids 41 (2006) 699-710.

[28] J. Song, J.W. Lee, M.S. Yu, S. Shin, B.S. Kim, H.H. Cho, Thermal characteristics of inclined plate impinged by underexpanded sonic jet, Int. J. Heat Mass Transf. 62 (2013) 223-229.

[29] F. Alvi, K. Iyer, Mean and unsteady flowfield properties of supersonic impinging jets with lift plates, in: 5th AIAA/CEAS Aeroacoustics Conference and Exhibit, 1999.

[30] A. Krothapalli, E. Rajkuperan, F. Alvi, L. Lourenco, Flow field and noise characteristics of a supersonic impinging jet, J. Fluid Mech. 392 (1999) 155-181.

[31] M. Behnia, S. Parneix, Y. Shabany, P.A. Durbin, Numerical study of turbulent heat transfer in confined and unconfined impinging jets, Int. J. Heat Fluid Flow 20 (1999) $1-9$.

[32] O. Caggese, G. Gnaegi, G. Hannema, A. Terzis, P. Ott, Experimental and numerical investigation of a fully confined impingement round jet, Int. J. Heat Mass Transf. 65 (2013) 873-882

[33] H. Lu, L. Yue, X. Chang, Flow characteristics of hypersonic inlets with different cowl-lip blunting methods, Sci. China, Phys. Mech. Astron. 57 (2014) 741-752.

[34] H.B. Lu, L.J. Yue, Y.B. Xiao, X.Y. Zhang, Interaction of isentropic compression waves with a bow shock, AIAA J. 51 (2013) 2474-2484.

[35] L.J. Yue, Y.A. Jia, X. Xu, X.Y. Zhang, P. Zhang, Effect of cowl shock on restart characteristics of simple ramp type hypersonic inlets with thin boundary layers, Aerosp. Sci. Technol. 74 (2018) 72-80.

[36] F.R. Menter, Two-equation eddy-viscosity turbulence models for engineering applications, AIAA J. 32 (1994) 1598-1605.

[37] A.R. Wieting, M.S. Holden, Experimental shock-wave interference heating on a cylinder at Mach 6 and 8, AIAA J. 27 (1989) 1557-1565.

[38] J. Häberle, A. Gülhan, Internal flowfield investigation of a hypersonic inlet at Mach 6 with bleed, J. Propuls. Power 23 (2007) 1007-1017.

[39] A.J. Musker, Explicit expression for the smooth wall velocity distribution in a turbulent boundary layer, AIAA J. 17 (1979) 655-657.

[40] J.D. Anderson, Hypersonic and High-Temperature Gas Dynamics, second edition, American Institute of Aeronautics and Astronautics, 2006.

[41] J. Syberg, J.L. Koncsek, Bleed system design technology for supersonic inlets, J. Aircr. 10 (1973) 407-413.

[42] H.J. Tan, S. Sun, H.X. Huang, Behavior of shock trains in a hypersonic inlet/isolator model with complex background waves, Exp. Fluids 53 (2012) 1647-1661. 